\title{
The Degree of Public School Principals' Implementation of Leadership Standards and its Relationship with the Administrative Efficiency
}

Saleh Mohammed Hawamdeh

\author{
A student of doctorate - Yarmouk University/Faculty of Educational /Department of Administration \\ Email:Salehhawamdeh123@gmail.com
}

\author{
Dr. Aref Tawfeeq Attari
}

Yarmouk University/Faculty of Educational /Department of Administration

Doi:10.5901/jesr.2016.v6n1p117

\section{Abstract}

\begin{abstract}
The purpose of this study was to identify the degree of public school principals implementation of leadership standards proposed by the Jordanian Ministry of Education and its relationship with the administrative efficiency from the perspective of supervisors. The research builds a questionnaire to measure the two domains, the degree of public school principals' implementation of leadership standards proposed by the Jordanian ministry of education, and The administrative efficiency. The sample consisted of (337) supervisors from the Ministry of Education. The results of the study indicated that the degree of public school principals' implementation of leadership standards, domains was high, and, the administrative efficiency was also high. Overall, the results showed that there was a positive correlation relationship between the leadership standards and the administrative efficiency. In the light of the results, the researcher recommended that, the ministry of education should review the traditional administrative methods and systems, and uses leadership standards, and the strategic planning as an administrative method. Schools principals should be motivated to consider the leadership standards proposed by MOE in their daily practice.
\end{abstract}

Keywords: Leadership standards, Administrative effectiveness, Supervisor

\section{Introduction}

Educational institutions are often driven by pressure to develop new mechanisms and methods in order to upgrade services, and to achieve greater quality and standards of excellence. Consequently, schools must be able to provide valuable human resource services through their school leaders who are critical in bringing effective school reform and development. In past decades the role of the principal was to teach and perform daily school tasks and then it extended to monitor teachers' performance, and to insure applying the Ministry of Education legislation. Shipman et al. (2007) argue that school leaders' responsibilities have increased in the last 50 years, shifting from an emphasis on management to a focus on leadership.

Gradually, the educational leadership concept has developed during the past years because of the recognition of the principal's role in making schools succeed; the school principal roles and responsibilities have shifted to a greater emphasis on leadership, including areas such as improving relationships between all levels of staff, students' parents and the community. Another role was focused on planning and self-development.

Badri, (2005) stated that the evolution of the concept of management in developing countries and the technological explosion reflected on educational administration concept, which represents an important pillar in the formation of the image of the future in the light of the knowledge age and population explosion. Lunenburg and Ornstein (2008) discussed the leadership role of the principal, who is ultimately considered responsible for all school functions and operations.

Historically, the changing concept of educational leadership leads to the necessity of establishing educational standards, which measure the effectiveness of school leaders and their success in anchoring their schools. However, Standards are not a new concept according to Ravitch (1995) the idea of standards is not new, and can be found in many religious references in which God is seen to be creating standards for the people. One example comes from the Old Testament book of Genesis, when God commands Noah, "Make thee an ark from resinous wood sealing it with pitch". 
Jordan as a leading country in educational reform in the Middle East has developed the Principal's leadership Standards during the past years to meet the new global changing and the technology expansion which affects in building a competitive learning society. In 2014, with cooperation of Education Reform Support Program (ERSP) the Ministry of education has developed standards to be adopted by the principals and supervisors, these standards can serve to underpin individuals' professional development, performance management and annual appraisal reviews.

\section{Literature Review}

\subsection{Standards}

Many researchers have indicated that standards play an important role in both organizational and individual professional improvement. Ravitch (1995), Brunsson and Jacobsson (2005) Cunningham (2009), Hannigan (2008) pointed out the importance of standards to the quality of life and make a strong argument that life without them may be impossible

According to Brunsson and Jacobsson (2005): Standards generate a strong element of global order in the modern world, such as would be impossible without them. Standards constitute rules about what those who adopt them should do, even if this only involves saying something or designating something in a particular way. More specifically, three types of standards can be distinguished: standards about being something, about doing something, or about having something. (Pp. 1, 4)

Ravitch (1995) stated that the idea of standards is not new, and can be found in many religious references in which God is seen to be creating standards for the people. One example comes from the Old Testament book of Genesis, when God commands Noah, "Make thee an ark from resinous wood sealing it with pitch" (p. 8).

Standards have also long been used for units of measurement such as length, volume, and weight- they developed between 7th century B.C. and 17th century A.D., in different parts of the world. Standards have been commonly used in production and manufacturing, (Shipman \& Queen, Henry, 2007). But from the 19th to the 20th centuries standardization became more recognized, and many industrialized countries started to develop better standards in order to improve performance, production, and service. (AlAnsari, 2012)

Educational standards serve to meet high academic standards in education, moreover, they provide adequate opportunities for researchers to achieve these high standards. Therefor during the past years it was noticeable that educators began to establish standards governing the educational process starting from foundations of success in international tests, learning outcomes measuring tools, curriculum standards, content and performance standards for students and teachers, schools quality and at last focused on principals' standards which enhance the role of principals in managing all the components of the educational process ; the staff, students ,parents, school environment and the community.

Increasingly, the need to improve the educational process through developing educational standards was evident in many countries around the world, each country has developed educational leadership standards according to its educational regulation, and principal's performance expectancy. Al Ansari (2012) conducted a quantitative research to identify the professional educational program standards that educators believed were needed and important for public school principals ,the survey addressed 10 educational leadership program standards used by the Ministry of Education in Kuwait, which were vision, school culture and instructional learning, management and operation, community relations, context ethics, context politics and law, technology, research, internship and mentoring .The results confirmed the usefulness of these 10 standards for establishing educational leadership programs for school principals in order to help them meet principal job expectations.

Cunningham (2009) examined the relationship between a large suburban school district's P-12 principals' perceptions of the importance of the (ELCC) standards and their use of the ELCC standards in their daily leadership roles The principals' overall perception of the importance of the Standards' Indicator for leadership means and their using mean of the ELCC standard were 3.00 or higher. It also indicated a high degree of consistency between the principals' views of the importance and the use of ELCC standards.

Historically, the U.S. began establishing several widely used standards in the early 20th century in business, education, health, and professional development programs. These include The Interstate School Leaders Licensures Consortium (ISLLC) which developed standards in 1996 based heavily on the research connections between educational leadership and productive schools. Further, they sought out significant trends in society and education that had implications for new views of leadership - and how the standards might give meaning to new perspectives on leadership. The purpose of establishing the standards was to offer school leaders a guide for continually monitoring their 
professional growth and development. The standards were also created to assist school executive programs in preparing leaders, provide districts with a focus, guide professional development programs for school executives, and offer a tool for the development of mentoring programs for new school executives (Barbour,2014)

The first version of the ISLLC Standards was released in 1996. Revisions for the 1996 ISLLC standards were adopted on December 12, 2007 as an attempt to prevent / limit confusion. In 1996 each standard began with "A school administrator is an educator leader who..." In 2008 each standard begins with "An education leader promotes the success of every student by..." Even though there has been a name change from ISLLC standards to Educational Leadership Policy Standards (Cunningham,, 2009)

A 2008 update provided important, but modest, revisions to the 1996 standards. The Standards have been recast in 2014 to better incorporate the expanding body of research and best practices from the field. Some components of the 2014 ISLLC Standards have been given more prominence and functions when compared to the 2008 version. This prioritization and clarification are most noticeable in the leadership domains that pertain to a school's instructional program, culture, and human capital management, and in the enrichment of the core dynamic of the Standards.

Council of Chief State School Officers (2014)

\subsection{The ISLLC Standards}

The National Policy Board on Educational Administration (NPBEA), has established the Interstate School Leaders Licensure Consortium standards (ISLLC) for the purpose of improving the school principal's leadership and management skills. These standards are:

- Standard 1: Vision and Mission: An educational leader promotes the success and well-being of every student by ensuring the development, articulation, implementation, and stewardship of a child-centered vision of quality schooling that is shared by all members of the school community.

- Standard 2: Instructional Capacity: An educational leader promotes the success and well-being of every student by enhancing instructional capacity.

- Standard 3: Instruction: An educational leader promotes the success and well-being of every student by promoting instruction that maximizes student learning.

- Standard 4: Curriculum and Assessment: An educational leader promotes the success and well-being of every student by promoting robust and meaningful curricula and assessment programs.

- Standard 5: Community of Care for Students: An educational leader promotes the success and well-being of every student by promoting the development of an inclusive school climate characterized by supportive relationships and a personalized culture of care.

- Standard 6: Professional Culture for Teachers and Staff: An educational leader promotes the success and well-being of every student by promoting professionally normed communities for teachers and other professional

- Standard 7: Communities of Engagement for Families: An educational leader promotes the success and wellbeing of every student by promoting communities of engagement for families and other stakeholders.

- Standard 8: Operations and Management: An educational leader promotes the success and well-being of every student by ensuring effective and efficient management of the school or district to promote student social and academic learning.

- Standard 9: Ethical Principles and Professional Norms: An educational leader promotes the success and well-being of every student by adhering to ethical principles and professional norms.

- Standard 10: Equity and Cultural Responsiveness: An educational leader promotes the success and wellbeing of every student by ensuring the development of an equitable and culturally responsive school.

- Standard 11: Continuous School Improvement: An educational leader promotes the success and well-being of every student by ensuring the development of a culture of continuous school improvement.

These Standards are based on an understanding of current research on education, leadership, and describe processes in which education leadership can drive student achievement

\subsection{The Educational Leadership Standards in Jordan}

The Jordanian educational leaders, faithfully believe in the important role of the school leaders in anchoring the change and coping with the new development therefor, they developed a set of new educational standards with cooperation of 
Education Reform Support Program (ERSP) and defining these standards in six main domains as follows:

1- Leadership, Values, vision: The principal exercises his leadership role, demonstrates strong values, ethical behavior and a clear mission based on the Ministry of Education's vision and mission.

2- Learning-Centered Leadership: The principal leads the school community towards providing better learning opportunities for students.

3- Planning and Evaluation: The principal plans to lead change and engages staff, students, parents and the community in building and implementing the school improvement plan (SIP) and engages them in evaluating its progress.

4- Communication: The principal communicates and involves others (teachers, students and local community) in decision -making to create a high performing school.

5- Resource management: The principal manages resources effectively to maximize the use of available resources to enhance school effectiveness.

6- Self-Development: The principal inspires others through personal, emotional and professional growth. (The Ministry of Education Standards, 2014)

Along with each standard are knowledge indicators and performance indicators, which can be used to guide the practice of public school principals. The aim of constructing these standard was to cope with the recent research findings on educational leadership which called for better administrative practices focusing on student's achievement and community engagement.

\subsection{Administrative efficiency}

The concept of administrative efficiency due to the classical management theories which focus on the idea that there are scientific principles of administration, and learning them increase the effectiveness and efficiency of management in the Organization, The management theories have evolved and have viewed as an open administrative system which interacted with what is happening in the external environment system and which is focusing on planning and bet to achieve efficiency. (Al-Mulhim, 2000).

Early forms of effective principal leadership focused on the principal's ability to manage school processes and procedures related to instruction and supervision. The concept of effectiveness and accountability of the principal is associated with the effectiveness of school and teachers, their high job satisfaction, the quality of education, and develop student learning, (Parylo \& Zbeda, 2014)

El-Akhras, (2009) defined the effective principal as someone who achieves the expected results and who is able to set goals clearly, and provides the necessary information to all colleagues, and shares the staff with the unexpected results.

Many researches demonstrated that a leadership is considered effective when it is driven by several factors such as individual values system, developing overall performance, achieving the expected objectives and results with high levels of learning, and interpersonal skills. Day, Harris \& Hadfield (2001), Parylo and Zepeda (2014). Scheerens (2000)

Grissom \& Loeb,( 2011) conceived the effective instructional leadership as combining an understanding of the instructional needs of the school with an ability to target resources where they are needed, hire the best available teachers, and keep the school running smoothly .Others related the concept of administrative efficiency to the principal's responsibilities which focuses on school management, developing learning and teaching process, in addition to shared vision, school alignment and coherence, teacher commitment to the school and teachers' support for students.Schwartz \& McKenna \& Mauer (2007) Hellinger and Lue (2014) .

In a study conducted in Characteristics of Effective School Principals. The researchers Lokman and Hamdan (2011) conducted a study which used interview as a study tool. They stated that in order to be effective leaders in school, principals needed to possess four important strategies or major themes labeled humanistic, teaching and learning, management skills and individual traits.

\subsection{Measuring organization efficiency}

Administrative efficiency is associated with the degree of ability to achieve the expected objectives. It is measured by:

1- The degree of ability to accomplish goals at minimum cost and effort.

2- Interaction and activity implemented by the leadership within the Organization.

3- Effective cooperation among the staff. (Nashwan, 2004). 
Al Shawaf (1989) noted that the concept of organizational effectiveness is determined by several factors such as: the idea of superiority, or organizational excellence, the ability of achieving the goals, exploiting the environment with scarce resources needed for survival,and the awareness of the interaction process of behavior and systems, and to ensures the needs of beneficiaries, recognize and accommodate competing values inside and outside the organization.

\section{Statement of the Problem}

The standards movement set forth by educators, policymakers, parents, business leaders, as a kind of accountability for school effectiveness. They associated it with the principal's role and his ability to achieve progress in students' performance and outcomes, and leading the school improvement in the changing world of knowledge and according to the workforce requirements. This force the educators to improve the environment in which teaching and learning occurs and they called for establishing a set of leadership standards to change the role of the principal from traditional phase into an innovative one.

The traditional role of principal has shifted into a modern leadership role with a clear vision and recognition to the accelerate change of knowledge .In light of this change, it was necessary to improve the principal's performance and their ability to transfer knowledge and improve the school environment(Abbawi,2007).

The Jordanian Ministry of Education was aware of the importance of the principal's leadership role in improving the school community and achieving the learner needs as well as the community welfare. The MOE started its professional programs for school leaders to increase their abilities and leadership effectiveness according to the modern educational theories. One of these programs was establishing a set of leadership standards in which the MOE can measure their effectiveness leadership role of both principals and supervisors. In light of that the problem of this study is to identify the degree of public school principals 'implementation of leadership standards proposed by the Jordanian Ministry of Education and its relationship with the administrative efficiency from the perspective of supervisor

\subsection{Research Questions}

1- What is the degree of public school principals 'implementation of leadership standards proposed by the JMOE from the perspective of supervisors?

2- Are there a significant difference at the significant level $(a==0.05)$ between the degree of public school principals 'implementation of leadership standards proposed by the JMOE and the administrative efficiency?

\subsection{The Objectives of the Study:}

The study aims to identify the degree of public school principals 'implementation of leadership standards proposed by the Jordanian Ministry of Education and its relationship with the administrative efficiency from the perspective of supervisors.

\subsection{Significance of the Study:-}

The importance of this study lies in two aspects:

The theatrical side: This study presents theoretical literature and information about evaluating school principals on the basis of certain criteria, its results will give a feedback to educational leaders as well as enabling them to monitor and evaluate educational leadership process, it also will form a reference for researchers and those interested in this area, since this study is the first of its kind in Jordan. As the adoption of standards were officially approved by JMOE for school leadership evaluation in 2014.

The practical side: The study suggests some recommendations for decision-makers in the Ministry of education and the educational planners to make appropriate decisions when planning Professional Development for principals according to the actual needs. They also can use the results to develop the proposed standards or add other areas in the light of the results of this study. 


\subsection{The study procedures, terms and definitions}

\subsubsection{Standards}

A term indicating the minimum events required for a specific purpose. (Mohammed, 2013). (Shihath, 2003) defines it as modeling rules and orders which are used to govern or to measure people and group behaviors. The researcher defines standards as a group of expectations and duties adopted by the principals for serving the educational system and students learning process.

\subsubsection{Administrative efficiency}

It's the leader's ability to achieve the expected results of the required targets. (Hawari, 1995). The researcher defines it as: the ability of the school leader to achieve his administrative goals as proposed by the MOE standards and according to the available resources.

\subsection{Limitations of the study}

The study was limited to sample of the educational supervisor from the northern educational directorates in the Hashemite Kingdom of Jordan in 2015.

\section{Method and Procedures}

This Chapter describes the methodology of the study and its population, sample, and the tools that were used to measure the degree of validity, reliability and the identification of the study variables, procedures and statistical processing which used to answer the research questions

\subsection{Research methodology}

The researcher used descriptive statistics to identify the degree of public school principals 'implementation of leadership standards proposed by the Jordanian Ministry of Education and its relationship with the administrative efficiency from the perspective of supervisors.

\subsection{Population and the sample:}

The sample consisted of all supervisors from (13) directorates of the northern area in the Hashemite Kingdom of Jordan. (317) supervisors participated in this study from (337) supervisors.(20) male and female supervisors were selected as an exploratory sample to be used for retest reliability.

Table (1): Population and sample

\begin{tabular}{|l|l|c|c|}
\hline Variable & Level of variables & Frequency & Percentage \\
\hline \multirow{3}{*}{ Gender } & Male & 242 & 77.3 \\
& Female & 71 & 22.7 \\
& Total & 313 & 100.0 \\
\hline \multirow{5}{*}{ Level of Education } & Diploma of Education & 41 & 13.1 \\
& Master's degree & 190 & 60.1 \\
& Doctorate's degree & 82 & 26.2 \\
& Totat & 313 & 100.0 \\
\hline \multirow{3}{*}{ Experience } & Less than 10 years & 65 & 20.8 \\
& More than 10 years & 248 & 79.2 \\
& Total & 313 & 100.0 \\
\hline
\end{tabular}




\subsection{The study tools}

This study was conducted with a quantitative research design .It used two surveys. The first one was officially proposed by the Jordanian Ministry of Education .It aimed to measure the degree of public school principals 'implementation of leadership standards proposed by the JMOE from the perspective of supervisors. It consisted of 60 items that addressed the educational standards which are: leadership, values and vision; Learning-Centered leadership; Communication; Resource Management and Self-Development. The second survey was prepared by the researcher to measure the administrative efficiency .It consisted of 28 items distributed on 6 domains which are: Vision and Mission; Planning; Communication; Decision-Making; Human Resource Leadership and Evaluation. The second survey was sent to experts and a feedback was received, items were added or deleted based on feedback from a total of 32 Jordanian Professors from Jordanian and Saudi universities.

\subsection{Validity}

\subsubsection{Content Validity}

The first survey based on the standards proposed by the JMOE. A five- point Likert scale was used to answer the items about the degree of principals 'implementation of leadership standards .It was ranked as followed very high (5points) high (4points) moderate(3points)weak(2points)and very weak(1 point).For achieving construct validity, the first tool was applied on an expletory sample consisted of 20 male and female supervisors who works in the northern educational directorates, and who are not from the targeted sample. Pearson correlation coefficient was used to estimate the intercorrelation between the proposed domains and their items.

\subsubsection{The Reliability of the first tool}

The Cronbach alpha coefficient was used to measure the degree of homogeneity of the items within each scale. This will help to understand the "internal consistency" of the second instrument, To verify the Stability of study tool and its items the researcher used a Test-Retest on the exploratory sample with two weeks in between.

Table (2): The values of internal-Consistency and Test-Retest of the first study tool.

\begin{tabular}{|l|c|c|c|}
\hline Domains \& Items & Internal Consistency & Test-Retest Reliability & $\mathrm{N}$ \\
\hline Leadership, Values and Vision & 0.94 & 0.84 & 9 \\
Learning-Centered Leadership & 0.94 & 0.81 & 11 \\
Planning and Evaluating & 0.96 & 0.79 & 15 \\
Communication & 0.95 & 0.82 & 11 \\
Resource Management & 0.94 & 0.85 & 9 \\
Self-Development & 0.91 & 0.88 & 5 \\
\hline Total & 0.99 & 0.83 & 60 \\
\hline
\end{tabular}

As noticed from the data in table (2) the internal-consistency reliability for the first study tool was (0.99) and it ranged (0.96-0.91) for its items. In comparison with the Test-Retest reliability which was (0.83) and its items ranged (0.88-0.79)

Table (3): Correction criteria

\begin{tabular}{|l|l|}
\hline The degree of application & Mean Categories \\
\hline Good & More than 3.49 \\
Average & $2.50-3.49$ \\
Bad & Less than 2.50 \\
\hline
\end{tabular}

\subsection{The Administrative efficiency tool}

Literature and previous studies were used to generate a list of standards for administrators efficiency ,The study tool consisted of 27 items . 


\subsubsection{The validity of the second tool}

To investigate the content validity of the second instrument, the researcher sent it to a group of 32 expertise from Universities' professors who are specialized in (educational administration, education foundation, curriculum ,general administration, measuring and evaluation). After receiving the feedback the researcher adjusted and added a new item to be 28 items in its last edit.

The study instrument consisted of (28) items distributed on these domains: Values and Mission which has 5 items; Planning and contains 4 items; Communication with 4 items; Decision -Making has also 4 items and 5 items for Human Resource and Evaluation contains 6 items.

A five- point Likert scale was used to answer the items about the administrative efficiency of the principals from the perspective of the supervisors. It ranked as followed very high (5points) high (4points) moderate (3points) weak (2points)and very weak (1 point).

The second tool was applied on an exploratory sample consisted of (20) male and female supervisors who works in the northern educational directorates and who are not from the purposeful sample, and that to estimate Pearson correlation coefficient.

\subsubsection{The Reliability of the second tool}

The Cronbach alpha coefficient was used to measure the degree of homogeneity of the items within each scale. This will help to understand the "internal consistency" of the second instrument, to verify the Stability of study tool and its items the researcher used a Test-Retest on an exploratory sample with two weeks in between.

Table (4): The values of internal-Consistency and Test-Retest of the second study tool

\begin{tabular}{|l|c|c|c|}
\hline Domains \&items & Internal Consistency & Test-Retest Reliability & $\mathrm{N}$ \\
\hline Vision and Mission & 0.93 & 0.83 & 5 \\
Planning & 0.92 & 0.88 & 4 \\
Communication & 0.91 & 0.85 & 4 \\
Decision -Making & 0.90 & 0.87 & 4 \\
Human resources & 0.91 & 0.82 & 5 \\
Leadership & 0.94 & 0.79 & 6 \\
\hline Total & 0.98 & 0.82 & 28 \\
\hline
\end{tabular}

Table (4) shows the internal-consistency reliability for the second tool which was $(0.98)$ and it ranged $(0.90-0.94)$ for its items. In comparison with the Test-Retest reliability which was (0.82) and its items ranged (0.79-0.88).

Table (5): Correction criteria

\begin{tabular}{|l|l|}
\hline The application degree & Mean category \\
\hline High & More than 3.49 \\
Average & $2.50-3.49$ \\
Bad & Less than 2.50 \\
\hline
\end{tabular}

\section{Procedures}

This study was conducted between May 17, 2015, and September7, 2015. In order to conduct the study survey, the researcher followed some formal and informal processes:

1. Obtaining an approval letter from Yarmouk University (Dean) to The MOE to allow the researcher to collect the data in its directorates.

2. Obtaining permission and approval from the Ministry of Education to collect data from the northern directorates, which required visiting the northern educational districts

3. Creating a timetable to help in organizing the procedures, photocopying the instrument and labeling them according to the northern districts, the name of the district, and the due date, contact information. In addition, the survey was placed in an envelope. 
4. Distributing the survey to the educational supervisors.

5. The researcher handed a hard copy of the study to higher education faculty and the superintendents.

6. Collecting the survey, and pursue the analysis procedures.

\subsection{The Variables}

1- The degree of public school principals 'implementation of leadership standards proposed by the Jordanian ministry of education from the perspective of supervisors.

2- The degree of principal's administrative efficiency from the perspective of supervisors.

\subsection{Statistical Processing}

The SPSS statistical software program was used for statistical analysis. To answer the questions of the study, means and standard deviations were estimated.

\section{The results}

This study aimed to identify the degree of public school principals 'implementation of leadership standards proposed by the Jordanian ministry of education and its relation with administrative efficiency from the perspective of supervisors. And that was by answering the study questions

1- What is the degree of public school principals 'implementation of leadership standards proposed by the JMOE from the perspective of supervisors?

2- Are there significant difference at the significant level $(a==0.05)$ between the degree of public school principals 'implementation of leadership standards proposed by the JMOE and the administrative efficiency?

\subsection{The results for the first question :}

The results were estimated by mean and standard deviation as presented in table (6)

Table (6):

\begin{tabular}{|c|c|l|c|c|c|}
\hline Rank & NO. & Leadership Standards Domains & M & SD & Degree \\
\hline 1 & 4 & Communication & 3.59 & 0.66 & High \\
\hline 2 & 5 & Resources Management & 3.59 & 0.63 & High \\
\hline 3 & 6 & Self-Development & 3.57 & 0.68 & High \\
\hline 4 & 1 & Values and vision Leadership & 3.53 & 0.66 & High \\
\hline 5 & 2 & Planning and Evaluation & 3.52 & 0.64 & High \\
\hline 6 & 3 & Learning-Centered Leadership & 3.47 & 0.66 & Moderate \\
\hline \multicolumn{2}{|l|}{ Total } & 3.54 & 0.60 & high \\
\hline
\end{tabular}

Table (6) indicates that the degree of implementing the proposed standards was high for all the proposed domain except for Learning-Centered Leadership which was moderate. The domains are ranked as follows: Communication, Resource Management, Self-Development, Values and visions planning and the last domain with a moderate level Learning Centered

\subsection{The result of the second question:}

Are there significant difference at the significant level $(a==0.05$ ) between the degree of public school principals 'implementation of leadership standards proposed by the JMOE and the administrative efficiency?

To answer this question Pearson correlation coefficient was used to estimate the correlation between the degree of public school principals 'implementation of leadership standards and its items which are proposed by the Jordanian Ministry of Education and the administrative efficiency and its items, from the perspective of supervisors. 
Table (7): The correlation coefficient between the degree of principal' implementation of the proposed standard and the administrative efficiency.

\begin{tabular}{|c|c|c|c|c|c|c|c|c|}
\hline Relation between & Statistic & $\begin{array}{c}\text { Vision } \\
\text { \&Mission }\end{array}$ & Planning & Communication & $\begin{array}{l}\text { Decision - } \\
\text { Making }\end{array}$ & $\begin{array}{c}\text { Human } \\
\text { Resources }\end{array}$ & Evaluation & Total \\
\hline \multirow{2}{*}{$\begin{array}{l}\text { Leadership, Values } \\
\text { \&Vision }\end{array}$} & \multirow{2}{*}{ correlation } & 0.74 & 0.70 & 0.71 & 0.70 & 0.71 & 0.68 & 0.77 \\
\hline & & 0.00 & 0.00 & 0.00 & 0.00 & 0.00 & 0.00 & 0.00 \\
\hline \multirow{2}{*}{$\begin{array}{l}\text { Learning-Centered } \\
\text { Leadership }\end{array}$} & \multirow{2}{*}{ correlation } & 0.76 & 0.72 & 0.77 & 0.73 & 0.70 & 0.70 & 0.80 \\
\hline & & 0.00 & 0.00 & 0.00 & 0.00 & 0.00 & 0.00 & 0.00 \\
\hline \multirow{2}{*}{ Planning \&Evaluation } & \multirow[b]{2}{*}{ correlation } & 0.80 & 0.77 & 0.78 & 0.80 & $0 ; 77$ & 0.76 & 0.75 \\
\hline & & 0.00 & 0.00 & 0.00 & 0.00 & 0.00 & 0.00 & 0.00 \\
\hline \multirow{2}{*}{ Communication } & \multirow{2}{*}{ correlation } & 0.76 & 0.78 & 0.80 & 0.78 & 0.75 & 0.73 & 0.83 \\
\hline & & 0.00 & 0.00 & 0.00 & 0.00 & 0.00 & 0.00 & 0.00 \\
\hline \multirow{2}{*}{ Resource Management } & \multirow{2}{*}{ correlation } & 0.75 & 0.74 & 0.75 & 0.75 & 0.72 & 0.71 & 0.80 \\
\hline & & 0.00 & 0.00 & 0.00 & 0.00 & 0.00 & 0.00 & 0.00 \\
\hline \multirow{2}{*}{ Self-Development } & \multirow[t]{2}{*}{ correlation } & 0.73 & 0.77 & 0.75 & 0.73 & 0.73 & 0.72 & 0.81 \\
\hline & & 0.00 & 0.00 & 0.00 & 0.00 & 0.00 & 0.00 & 0.00 \\
\hline \multirow{2}{*}{ Total } & \multirow{2}{*}{ correlation } & 0.83 & 0.82 & 0.83 & 0.82 & 0.80 & 0.78 & 0.89 \\
\hline & & 0.00 & 0.00 & 0.00 & 0.00 & 0.00 & 0.00 & 0.00 \\
\hline
\end{tabular}

As illustrated in this table all the correlation between the degree of public school principals 'implementation of leadership standards proposed by the Jordanian ministry of education and the administrative efficiency from the perspective of supervisors show a positive significant at level $(\alpha=0.05)$ and it also indicates strong correlation according to scale (Hinkle,Wiersma,Jurs,1988) Whereas, the correlation between the degree of principals 'implementation the leadership standard proposed by the MOE (leadership, values \&vision ) domains and the administrative domain for (Evaluation ) was moderate.

\section{Discussion of the Result and Recommendations}

Study conducted the following results. Each was explained according to the study questions:

What is the degree of public school principals 'implementation of leadership standards proposed by the JMOE from the perspective of supervisors?

The main goal of this study was to identify the degree of public school principals 'implementation of leadership standards proposed by the JMOE from the perspective of the supervisors. Overall, The result shows that the degree of implementing the leadership standard by the principals from the perspective of the supervisors was high in all levels as shown in table (6). The result reflects the acceptance of the supervisors towards principal's implementation of leadership standards in general, and to their implementation of communication domain and to the way they interact with others and how they use the items of human resources to manage their school resources, in addition to their awareness of the important role of setting clear vision, planning and self-development in developing their performance. The results of this study also confirmed what previous studies indicated about the principal's implementation of the educational standards as a guide in their leadership role, Cunningham (2009), Hannigan (2008)

The results indicate that, all the items of the proposed standards from the perspective of the supervisors were also high. As shown in table (6) they were ranked as follows: communication comes at the first level with the mean (3.95) and SD (0.66). Human resource implementation was high too with the mean (3.59) and SD (0.63).followed by selfdevelopment which it measurements shows a high degree in estimating its mean (3.57) and (0.68) for its standard deviation. The fourth domain, Leadership value and vision shows a high degree too. It has a rate of (3.52) for the mean average and (0.66) for the standard deviation. The principal's implementation of planning and evaluations was high with (3.52) as for the men and (0.64) for the SD. All the previous domain implementation shows a high degree except for the last learning-centered leadership which has a moderate degree in (3.47) for its mean, and its standard deviation was (0. 66) The result confirms the significant role of effective educational leadership standard in Self-development and in directing leaders towards good school managing

Are there a significant difference at the significant level $(\alpha==0.05)$ between the degree of public school principals 'implementation of leadership standards proposed by the JMOE and the administrative efficiency?

To answer this question Pearson correlation coefficient was used, as shown in table ( 7 ) there is a significant positive relationship at the level $(\alpha=0.05)$ between the MOE proposed standards and the level of administrative efficiency 
for all the domains and their items except for (Evaluation)which was moderate. The results also indicates that the principals' implementation of the proposed standard has efficiently affected their administrative practices, the results confirms what was conducted in Adams(2007) study, which showed a significant relation between administrative leadership and administrative efficiency. The results also supported what recent studies point to as there is significant correlation between the effective principals and leadership with school effectiveness and achievements (Williams 2008; Leithwood et al. 2005; Cotton 2003. Lokman and Said, 2011)

Implementing the educational standards in school management will enhance the principal's ability to set clear and purposeful plans for school improvement the items of each standards qualify principals to use their goals and vision in planning for the school culture development as they can prepare professional training for the teachers,motivate the staff to use the newest educational strategies which will reflect on student progress. It will also help the principals to find suitable ways to engage parents, community in school improvement and decision-making.

\section{Recommendations}

In accordance to the conducted results the researcher recommended the following suggestions:

1- The ministry of education should review the traditional administrative methods and systems and starts using strategical planning as an administrative style for principle to cope with the internal and external environment.

2- School principals should implement all the items of the proposed standards equally, and focus more on the learning process.

3- The ministry of education should hold more training programs on leadership standards.

4- The ministry of education should focus on Learning -centered leadership as the purpose of every educational process is achieving progress in students' outcomes.

\section{References}

Adams, Jerry .(2007). Development and Testing of an Initial Model of

Alansari, Amal, E.(2012). A Survey of Leadership standards for Professional Preparation of Public School Principals in Kuwait. Unpublished Doctoral Dissertation, USA: Andrews University.

Abbawi,Z,Moneer(2007). Recent trends in administrative organizations.Amman.Al Shoruk publication.

Akhras, Ismail Abbas. (2009). the Director of the school, and trends in educational administration. Oman, Ensign House for publishing and distribution.

Al-Mulhim, Ibrahim Ben Ali. (2000). Organizational development and change management in the public sector, Arab paper presented to Conference on creativity and innovation in the Department in meeting the challenges of the twenty-first century, the Arabic Organization for administrative development, Cairo, 6-8 November, 2000.

Al-shawaf, said Ali. (1989). measuring organizational effectiveness variables: a proposed framework. The journal of the Institute of public administration, (61) 19-49.

Barbour, Nancy Nicholson. (2014). Principal Leadership and Standards: Lessons Learned in Three Rural High Schools that Participated in North Carolina's Turnaround Initiative. Unpublished Doctoral Dissertation, USA: Carolina State University.

Brunsson, N., \& Jacobsson, B. (2005). A world of standards. New York, NY: Oxford University Press

Cotton, K. (2003). Principals and student achievement: What the research says. Alexandria, VA: Association for Supervision and Curriculum Development Council of chief state school officers/(2014)

Cunningham, Gregory. (2009). The Importance And Use Of The Educational Leadership Constituent Council (Elcc) Standards As Perceived By P-12 Principals In A Large Suburban School District. Unpublished Doctoral Dissertation, USA : Mercer

Day.Christopher,Harris.Alma,Hadfield.Mark.(2001) Grounding Knowledge of Schools

in Stakeholder Realities: AMulti-Perspective Study of Effective School Leaders.

School Leadership \& Management, Vol. 21, No. 1, pp. 19-42, 2001

Grissom ,Jason A Loeb, Susanna.(2011). Triangulating principal effectiveness: How perspectives of parents, teachers, and Assistant principals identify the central Importance of managerial skills. American Educational Research Journal. Month XXXX, Vol. XX, No. X, pp. 1-33

Hannigan, Peter, W.(2008). A Study of the Principal ship: Performance Indicators of Leadership Standards and the Work of Principals. USA: Northern Illinois University

Hawari, master (1995). The effective Director: 5 styles of managers. Cairo: Ain Shams.

Philip Hallinger, Philips \& Lua, Jiafang (2014). Modelling the effects of principal leadership and school capacity on teacher professional learning in Hong Kong primary schools. School Leadership \& Management:Formerly School Organization. 34:5, 481-501, DOI:10.1080/13632434.2014.938039

Leith wood, K., \& Jantzi, D. (2005). A review of transformational school leadership research: 1996-2005. Leadership and Policy in Schools, 4(3), 177-199. 
Lokman, Tahir, Hamdan Said.(2014). Characteristics of Effective School Principals, University Technology, Malaysia. http://www.studymode.com/essays/Chracteristics-Of-Effective-School-Principals-627772.html

Lunenburg, F. C., \& Ornstein, A. C. (2008). Educational administration: Concepts and practice (5th ed.). Belmont, CA: Wadsworth Publishing

Parylo, Oksana, Zepeda, Sally.(2014). Describing an effective principal: Perceptions of the central office leaders. School leadership \& Management. Vol, 34, No, 5, 518-537, Routledge.

Ravitch, Dian. (1995).National Standard in American Education. USA :Library of congress.

Scheerens, Japp.(2000) .Improving school effectiveness. Paris :UNSCO.

Schwartz, J., McKenna, B., Mauer, M. (2007). Stanford report outlines common elements of highly effective school principal training and development programs [Adobe Digital Editions version]

Shehata,Hassen (2003). Glossary of educational and psychological. Cairo: Egyptian Lebanese Casablanca.

Shipman, Neil, J., Queen, J., Allen, Apeel, Henry.(2007). Transforming School Leaders with ISLLC and Elcc. New York: Routledge. 